\title{
Social and environmental factors modulate leucocyte profiles in free-living Greylag geese (Anser anser)
}

\author{
Didone Frigerio $^{\text {Corresp., }}{ }^{1,2}$ ， Sonja C. Ludwig ${ }^{1,3}$ ， Josef Hemetsberger ${ }^{1,2}$ ， Kurt Kotrschal ${ }^{1,2}$, Claudia A. F. Wascher \\ 1,4 \\ ${ }^{1}$ Core facility Konrad Lorenz Forschungsstelle for Behaviour and Cognition, University of Vienna, Grünau im Almtal, Austria \\ 2 Department of Behavioural Biology, University of Vienna, Vienna, Austria \\ 3 Game \& Wildlife Conservation Trust, The Coach House, Eggleston Hall, Barnard Castle, United Kingdom \\ 4 Department of Life Sciences, Anglia Ruskin University, Cambridge, United Kingdom \\ Corresponding Author: Didone Frigerio \\ Email address: didone.frigerio@univie.ac.at
}

Background. Blood parameters such as haematocrit or leucocyte counts are indicators of immune status and health, which can be affected, in a complex way, by exogenous as well as endogenous factors. Additionally, social context is known to be among the most potent stressors in group living individuals, therefore potentially influencing haematological parameters. However, with few exceptions, this potential causal relationship received only moderate scientific attention. Methods. In a free-living and individually marked population of the highly social and long-lived Greylag goose, Anser anser, we relate variation in haematocrit $(\mathrm{HCT})$, heterophils to lymphocytes ratio $(\mathrm{H} / \mathrm{L})$ and blood leucocyte counts to the following factors: intrinsic (sex, age, raising condition, i.e. goose- or handraised), social (pair-bond status, pair-bond duration and parental experience) and environmental (biologically relevant periods, ambient temperature) factors. Blood samples were collected repeatedly from a total of 105 focal birds during three biologically relevant seasons (winter flock, mating season, summer). Results. We found significant relationships between haematological parameters and social as well as environmental factors. During the mating season, unpaired individuals had higher HCT compared to paired and family individuals and this pattern reversed in fall. Similarly, H/L ratio was positively related to pair-bond status in a seasonally dependent way, with highest values during mating and successful pairs had higher $\mathrm{H} / \mathrm{L}$ ratio than unsuccessful ones. Also, absolute number of leucocytes tended to vary depending of raising condition in a seasonally dependent way. Discussion. Haematology bears a great potential in ecological and behavioural studies on wild vertebrates. In sum we found that HTC, H/L ratio and absolute number of leucocytes are modulated by social factors and conclude that they may be considered valid indicators of individual stress load. 


\section{Title:}

2 Social and environmental factors modulate leucocyte profiles in free-living Greylag geese (Anser

3 anser)

\section{Authors:}

5 *Didone Frigerio ${ }^{1,2}$, Sonja C. Ludwig ${ }^{1,3}$, Josef Hemetsberger ${ }^{1,2}$, Kurt Kotrschal ${ }^{1,2}$ and Claudia A. F.

6 Wascher ${ }^{1,4}$

\section{Authors' affiliations and current addresses:}

$8{ }^{1}$ Core facility Konrad Lorenz Forschungsstelle for Behaviour and Cognition, University of

9 Vienna, Fischerau 11, A-4645 Grünau im Almtal, Austria.

$10{ }^{2}$ Department of Behavioural Biology, University of Vienna, Althanstrasse 14, A-1090 Vienna,

11 Austria.

$12{ }^{3}$ Game \& Wildlife Conservation Trust, The Coach House, Eggleston Hall, Barnard Castle, DG12

13 OAG, United Kingdom

$14{ }^{4}$ Department of Life Sciences, Anglia Ruskin University, Cambridge CB1 1PT, UK

15 *Corresponding author: didone.frigerio@univie.ac.at; Core facility KLF, University of Vienna,

16 Fischerau 11, A-4645 Grünau im Almtal, Austria.

17 Short title: Leucocyte profiles in Greylag geese (Anser anser)

18 Keywords: Greylag geese, Anser anser, haematology, haematocrit, differential leucocyte count,

19 seasonal patterns, age, sex, social status

20 Word count: 7778 


\section{Abstract}

23 Background. Blood parameters such as haematocrit or leucocyte counts are indicators of

24 immune status and health, which can be affected, in a complex way, by exogenous as well as

25 endogenous factors. Additionally, social context is known to be among the most potent

26 stressors in group living individuals, therefore potentially influencing haematological

27 parameters. However, with few exceptions, this potential causal relationship received only

28 moderate scientific attention.

29 Methods. In a free-living and individually marked population of the highly social and long-lived

30 Greylag goose, Anser anser, we relate variation in haematocrit (HCT), heterophils to

31 lymphocytes ratio(H/L) and blood leucocyte counts to the following factors: intrinsic (sex, age,

32 raising condition, i.e. goose- or hand-raised), social (pair-bond status, pair-bond duration and

33 parental experience) and environmental (biologically relevant periods, ambient temperature)

34 factors. Blood samples were collected repeatedly from a total of 105 focal birds during three

35 biologically relevant seasons (winter flock, mating season, summer).

36 Results. We found significant relationships between haematological parameters and social as

37 well as environmental factors. During the mating season, unpaired individuals had higher HCT

38 compared to paired and family individuals and this pattern reversed in fall. Similarly, $\mathrm{H} / \mathrm{L}$ ratio

39 was positively related to pair-bond status in a seasonally dependent way, with highest values

40 during mating and successful pairs had higher $\mathrm{H} / \mathrm{L}$ ratio than unsuccessful ones. Also, absolute

41 number of leucocytes tended to vary depending of raising condition in a seasonally dependent 42 way. 
43 Discussion. Haematology bears a great potential in ecological and behavioural studies on wild

44 vertebrates. In sum we found that HTC, H/L ratio and absolute number of leucocytes are

45 modulated by social factors and conclude that they may be considered valid indicators of

46 individual stress load.

47 


\section{Introduction}

Haematocrit (HCT) and differential leucocyte count are important diagnostic tools in gaining information about an animal's condition and health and may be regarded as indicators of individual responses to environmental and social conditions (Cooper 1975; Gavett \& Wakeley, 1986; Hellgren, Vaughan \& Kirkpatrick, 1989; Averbeck, 1992; Saino et al., 1997; Ots, Murumägi \& Hõrak, 1998; Bortolotti et al., 2009; Vinkler et al., 2010).

$$
\text { In wild birds HCT, i.e. the relative volume of red blood cells compared to the total blood }
$$
volume (Harrison \& Harrison, 1986), has been used to indicate the animals' physical condition (e.g. Saino et al., 1997; Ots, Murumägi \& Hõrak, 1998) and is known to decrease in response to stressful conditions (Dickens, Earle \& Romero, 2009). However, HCT also varies with sex, age, reproductive status, as well as geographic distribution (Rehder, Bird \& Laguë, 1982; Rehder et al., 1982; Dawson \& Bortolotti, 1997a; Dawson \& Bortolotti, 1997b; Bearhop et al., 1999; Potti et al., 1999; Fair, Whitaker \& Pearson, 2007).

$$
\text { The differential leucocyte count may be regarded as a proper proxy of individual immune }
$$
function (Dufva \& Allander, 1995; Zuk, Johnsen \& MacLarty, 1995; Johnsen \& Zuk, 1998), providing information on the relative occurrence of different leucocyte types. Absolute leucocyte numbers generally scale negatively with body condition (as an indicator of health, see Verhulst, Oosterbeek \& Bruinzeel, 2002). In birds, heterophils are rather indicative of changes in the environment (Gross \& Siegel, 1983; Maxwell \& Robertson, 1998). As lymphocyte numbers decrease while heterophil numbers increase in response to stressful conditions, the 
70 ratio of heterophils/lymphocytes ( $\mathrm{H} / \mathrm{L}$ ratio) is used as an indicator of physiological stress (e.g.

71 Gross \& Siegel, 1983, 1986; McFarlane \& Curtis, 1989; Maxwell, 1993; Vleck et al., 2000; Lebigre

72 et al., 2012). Finally, monocytes are long-lived phagocytic cells associated, together with other

73 leukocyte types (e.g. eosinophils, basophils), with defence against infections and bacteria (Davis

74 et al., 2008).

76 Social interactions are known to be among the most potent stressors in group living

77 individuals (von Holst, 1998; de Vries, Glasper \& Detillion, 2003). Therefore, it may also

78 influence haematological parameters. However, with the exception of a few veterinary studies

79 (e.g. Zakari et al., 2014; Arfuso et al., 2016), this potential causal relationship (i.e. social context

80 and haematology) received only moderate scientific attention. In Black-capped Chickadees

81 (Poecile atricapillus), for example, dominant males had higher haematocrits compared to

82 subordinates (van Oort et al., 2007) and in yellow baboons (Papio cynocephalus) frequent

83 involvement in aggressive encounters was related with decreased lymphocyte count (Alberts,

84 Sapolsky \& Altmann, 1992). On the other side, several studies suggest a relationship between

85 steroid hormones and haematocrit (e.g. a positive one with testosterone in White-plumed

86 Honeyeaters Lichenostomus penicillatus and American Kestrels Falco sparverius, Rehder,

87 Bird \& Laguë, 1982; a negative one with corticosterone in both sexes of two species of

88 longspurs, Calcarius ornatus and C.mccownii, Lynn, Hunt \& Wingfield, 2003; for a review see

89 Fair, Whitaker \& Pearson, 2007), even though the exact mechanisms remain unclear. 
91 We investigated variation in haematocrit and blood leucocytes in relation to endogenous

92 (age, sex) and exogenous factors (social status, season) in a free living and individually marked

93 population of the socially complex greylag geese, Anser anser (Lorenz, 1988; Kotrschal,

94 Hemetsberger \& Weiß, 2006; Kotrschal, Scheiber \& Hirschenhauser, 2010; Hemetsberger,

95 Scheiber \& Weiß, 2013). Social context is known to be among the strongest modulators of the

96 physiological stress responses in greylag geese (e.g. Wascher, Scheiber \& Kotrschal, 2008;

97 Wascher, Arnold \& Kotrschal, 2008; Wascher et al., 2009; Kralj-Fiser et al., 2010), which in turn

98 are alleviated via emotional social support by partners (Frigerio et al., 2003; Scheiber et al.,

99 2005; Scheiber, Kotrschal \& Weiß, 2009; Wascher et al., 2012). Across seasons, males and

100 females are faced with different demands (Kotrschal, Scheiber \& Hirschenhauser, 2010);

101 consequently, physiological changes, such as levels of corticosterone, co-vary with seasonal

102 variation in behaviour (Hirschenhauser, Moestl \& Kotrschal, 1999a; Hirschenhauser, Moestl \&

103 Kotrschal, 1999b; Frigerio et al., 2004a). The reproductive season of greylag geese starts in

104 January. Testosterone and corticosterone levels increase over the season (Kotschal,

105 Hirschenahuser \& Moestl, 1998; Hirschenhauser, Moestl \& Kotrschal, 1999a), as do agonistic

106 encounters between individuals (Lorenz, 1988). With the beginning of the breeding season

107 (March to July) the flock disintegrates into pairs. As for most bird species, reproduction in geese

108 is energetically costly, especially for the females who lay and incubate the eggs (Raveling, 1979;

109 Thompson \& Raveling, 1988). Parental geese show elevated corticosterone levels (Kotschal,

110 Hirschenahuser \& Moestl, 1998) and synchronise their moult with the rearing period, so that

111 they start flying again together with their offspring, when the goslings are approximately 10

112 weeks old (Lorenz, 1988). In alignment with the parental phase (i.e. from hatching to fledging), 
113 androgen levels reach their annual minimum in both sexes. The flock re-unites in August after

114 moulting, when androgens reach a second peak in unpaired males, while in paired individuals

115 the second peak is reached later in fall (Hirschenhauser, Moestl \& Kotrschal, 1999a;

116 Hirschenhauser, Moestl \& Kotrschal, 1999b). This hints at the close interplay between

117 physiology and social status in greylag geese, as suggested by further studies (e.g. stress

118 response and social allies: Sachser et al., 1998; heart rate in the context of sociality: Aureli,

119 Preston \& de Waal, 1999; steroid hormones and social status: Wingfield, Hegner \& Lewis, 1991;

120 Goymann et al., 2015).

121 We studied seasonal and individual variation in HCT and leucocyte counts. We tested

122 whether (a) individual factors, such as sex, age or raising condition, (b) social factors, such as

123 pair-bond status, (c) biologically relevant periods (mating season, after moult, autumn), or a

124 combination of the above, accounted for variation in haematological parameters. We

125 hypothesized that individuals of different sexes and social status (females and males, paired

126 versus unpaired) are faced with different social and energetic demands within the flock (e.g.

127 Metcalfe, Taylor \& Thorpe, 1995; Senar et al., 2000), which in turn, will affect the immune

128 system and will be manifest in HCT and leucocyte count. Since the mating season is socially and

129 energetically more challenging than moult and the stable winter flock (Drent \& Daan, 1980) we

130 predict that both haematological measurements will peak during this period, particularly in the

131 high-ranking parental individuals. Furthermore, we expect to find seasonal differences between

132 males and females, contingent with behavioural and physiological differences between the

133 sexes depending on an individual's social environment (Wingfield et al., 1991; Kotschal,

134 Hirschenahuser \& Moestl, 1998; Hirschenhauser, Moestl \& Kotrschal, 1999a Hirschenhauser, 
135 Moestl \& Kotrschal, 1999 b; Owens \& Hartley, 1998; Wascher et al., 2012; Lees et al., 2015).

136 Additionally, as hand-raised individuals generally differ from parent-raised conspecifics in

137 glucocorticoid stress reactivity (Hemetsberger et al., 2010), we finally predict that hand-raised

138 geese will show higher values of both haematological parameters during socially challenging

139 periods than parent-raised ones.

141

\section{Material and methods}

\section{Ethical statement}

144 This study complies with all current Austrian laws and regulations concerning the work with 145 wildlife. Catching and blood sampling of focal individuals was permitted under Animal

146 Experiment License Nr. 66.006/0010-II/10b/2010 by the Austrian Federal Ministry for Science 147 and Research.

Study area and focal animals

150 The Konrad Lorenz Research Station (KLF) is situated at $550 \mathrm{~m}$ above sea level in the valley of

151 the river Alm in the Northern part of the Austrian Alps $\left(47^{\circ} 48^{\prime} \mathrm{E}, 13^{\circ} 56^{\prime} \mathrm{N}\right)$. The non-migratory

152 flock of greylag geese we studied was introduced by Konrad Lorenz and co-workers in 1973

153 (Lorenz, 1988). The geese are unrestrained and generally spend the day close to the research

154 station where they are provided with supplemental food (pellets and grain) twice a day year-

155 round. At night, the birds roost on a lake approximately $10 \mathrm{~km}$ to the South (Almsee). As in wild 156 populations, natural predators (mainly red foxes, Vulpes vulpes and golden eagles, Aquila 
157 chrysaetos) may account for losses up to $10 \%$ of the flock per year (Hemetsberger, 2001,

158 Hemetsberger, 2002). All geese are marked with coloured leg rings and are habituated to the

159 close presence of humans. They neither show increased immunoreactive corticosterone

160 metabolites in their droppings nor heart rate increases when approached by familiar humans

161 (Scheiber et al., 2005; Wascher et al., 2012). Social behaviour and individual life-history data

162 have been monitored since 1973. Such long-term observations provide reliable information

163 about an individual's social relationships within the flock (i.e. paired or not). Approximately 20

$164 \%$ of the flock members are carefully hand-raised in the frame of specific research projects.

165 Details about the hand-raising tradition of the KLF are published elsewhere (Hemetsberger,

166 Scheiber \& Weiss, 2013). During the period of data collection (autumn 2010 to spring 2013) the

167 number of geese in flock varied between 153 and 157 individuals.

168 Focal animals of the present study were 105 greylag geese of different age (at the time of

169 sampling ranging from 0.16 to 22.81 years, mean age $\pm S E=5.06 \pm 0.36$ ), sex (67 males, 49

170 females), social status (68 paired individuals, 30 family individuals, 18 unpaired ones,) and

171 different raising condition (71 goose-raised and 45 hand-raised individuals).

172

173 Data collection

174 Data were collected during three phases, representing biologically relevant periods of the

175 year (Hemetsberger, Scheiber \& Weiß, 2013): (1) in summer, after moulting; (2) in autumn

176 (winter flock) and (3) during the mating season before the beginning of the laying period

177 (approx. mid-March). Focal geese were caught by hand up to three times, once in each period

178 either by a familiar human observer who approached the geese from the back and picked them 
179 up when being close enough or in a 'trapping enclosure', which the geese entered voluntarily

180 during feeding. In this way, chases or strong wing flapping were avoided. To control for diurnal

181 variation of the focal parameters, all geese were sampled in the morning between 0730 and

1820930.

183 Weather data were provided by a weather station in Grünau ( $47^{\circ} 51^{\prime} \mathrm{E}, 13^{\circ} 57^{\prime} \mathrm{N}$ ) operated

184 by Max Rauscher (www.gruenau.tv; last accessed 25 December 2014). Temperature data were

185 recorded every $5 \mathrm{~min}$, for which we calculated daily means during our analysis.

186

187 Blood samples

188 A total number of 169 blood samples ( $N=105$ individuals, Table 1$)$ were collected by

189 puncturing the tarsal vein with a sterile needle ( $24 \mu \mathrm{m}$ diameter) and collecting blood in two

190 heparinized micro-haematocrit capillaries $(75 \mathrm{~mm})$. Furthermore, we measured tarsus, beak

191 and wing length, and body weight. The whole procedure lasted less than 7 minutes per

192 individual.

193

194 In order to determine an individual's blood cell count (Prinzinger, Misovic \& Nagel, 2012)

195 one drop of blood was smeared onto a microscope slide, air-dried and stored until later

196 identification of leucocytes at the Clinical Pathology Platform of the University of Veterinary

197 Medicine in Vienna (Austria). Differential blood cells count provided information on absolute

198 leucocyte number/ $\mu$ I (LEUCO) and the relative occurrence of different leucocyte types

199 (heterophils, lymphocytes, monocytes, basophils and eosinophils, Prinzinger, Misovic \& Nagel,

200 2012). Blood smears were Romanowsky-stained with Haemaquick (E. Lehmann GmbH, Salzburg 
201 Austria) and microscopically evaluated. Thereafter, 100 white blood cells were differentiated

202 into heterophilic, eosinophilic or basophilic granulocytes, monocytes, and lymphocytes at

203 1,000x magnification using oil immersion. Results were provided in percentages.

204

205

The haematocrit capillaries were then sealed with plasticine at the bottom and centrifuged at $8000 \mathrm{rpm}$ for $5 \mathrm{~min}$ in order to determine the HCT. Volumes of red blood cell and plasma respectively were measured on the capillaries to the nearest $0.5 \mathrm{~mm}$ with calipers. HCT was then calculated as ratio as follow (Prinzinger, Misovic \& Nagel, 2012): red blood cell volume/(red blood cell volume + plasma volume). The individual arithmetic mean of the two HCT values was then taken into further analyses.

\section{Statistical analysis}

213 We ran linear mixed effect models (LMMs) fitted with maximum likelihood using the nlme

214 package (Pinheiro et al., 2015; model formulation and computational methods are described in

215 Lindstrom \& Bates 1990) in R (R Core Team 2015). Haematocrit, heterophils to lymphocytes

$216(\mathrm{H} / \mathrm{L})$ ratio, leucocyte numbers and percentage of monocytes were considered each in turn as

217 response variable and four LMMs were calculated for each of the three data subsets. Subset (1)

218 included all 169 samples collected from 105 individuals. We tested 7 competing hypotheses: (a)

219 individual factors accounting for variation in haematological parameters with sex, age (i.e. days

220 of life) and raising condition (hand-raised, goose-raised) included as fixed factors; (b) social

221 factors (pair-bond status: unpaired, paired, family) explaining variation in haematological

222 parameters; (c) biologically relevant period (mating season, after moult, autumn) accounting 
223 for variation in haematological parameters; (d) Social factors (pair-bond status) explaining

224 variation in a seasonally dependent way (the interaction between season and pair-bond status

225 was additionally included in the model); (e) individual factors (sex, age, raising-condition),

226 season and the interactions between season and individuals were included in the model; ( $\mathrm{f}$ )

227 individual factors, pair-bond status and the interaction between individual factors and pair-

228 bond status; (g) null model. Subset (2) included only data from male-female pair bonded

229 individuals (68 samples from 50 individuals). We tested three hypotheses: (a) pair-bond

230 duration, defined as 'established' if the pair spent already one breeding season together or

231 'newly', if this was not the case or (b) parental experience, i.e. if the pair previously successfully

232 raised fledged offspring (yes/no), accounting for variation in haematological parameters; (c)

233 null model.

234

235 The third subset of data only included individuals from which morphological measurements

236 were collected besides blood samples (116 samples from 70 individuals). A model including the

237 body size index (BSI), calculated as ratio weight/tarsus (as indicator for body's structural size,

238 sensu Green 2001) as fixed factor, was tested against the null model. In order to account for

239 repeated measures for each observed individual, the individual identity was included as random

240 factor. We based our model selection on corrected Akaike's Information Criterion values (AICC).

241 We calculated the difference between the best model and each other possible model $(\Delta \mathrm{AICc})$

242 and ranked the model combinations according to their $\triangle \mathrm{AICc}$, which provides an evaluation of

243 the overall strength of each model in the candidate set. Different competing models tested are

244 presented in Table 2. If multiple models qualified as the similarly good models, i.e. $\Delta$ AIC $\leq 2$ 
245 (Burnham \& Anderson, 2002; Burnham, 2004) we applied a model averaging approach, which

246 calculates model averaged parameters using the MuMIn package (version 1.15.6). In both data

247 subset (2) pair-bonded individuals and (3) morphological measures, for some of the parameters

248 the candidate models did not qualify as better as compared to the null model (Table 2) and are

249 therefore not presented in the results section.

250

251

252 Results

253 (1) Full dataset:

254 The best candidate model explaining variation in haematocrit included individual factors

255 (sex, age, raising condition), season as well as the interactions between season and individual

256 factors. HCT significantly increased with age in autumn but not during the mating season or

257 after moult (Table 3). The opposite pattern was found for percentage of monocytes, which

258 tended to decrease with age in autumn. The $\mathrm{H} / \mathrm{L}$ ratio varied depending on pair-bond status in a 259 seasonally dependent way (Figure 1).

260

261 Leucocyte counts differed depending on pair-bond status in a seasonally dependent way.

262 Generally, leucocyte counts were highest after moult (family, mean \pm SD: $11086.956 \pm$

263 4494.067) and in autumn (unpaired: $13125 \pm 6300.51$; paired: $13175 \pm 4948.741$; family:

$2649519.23 \pm 3548.184$ ) and decreased during the mating season (unpaired: $7933.333 \pm 2651.303$;

265 paired: $10500 \pm 5154.748$; family: $9200 \pm 2111.194)$. This decrease was most pronounced in 266 unpaired individuals as compared to paired and family individuals. Further, leucocyte counts 
267 tended to vary seasonally, depending on individual raising condition. In the winter leucocyte

268 counts were higher in hand-raised as compared to goose raised individuals (hand-raised:

269 13722.222 \pm 5248.24 ; goose-raised: $10050 \pm 3645.861)$ and this pattern reversed during the

270 mating season (hand-raised: $9468.75 \pm 4870.810$; goose-raised: $9715.909 \pm 3901.993)$. In

271 summer (after moult) only hand-raised individuals were sampled (11086.956 \pm 4494.067$)$.

272

273 (2) Pair-bonded individuals dataset

$274 \mathrm{HCT}$, leucocyte number, and percentage of monocytes were not significantly affected by

275 pair-bond duration or parental experience. H/L ratios were higher in pairs with an 'established'

276 pair-bond duration compared to those with a 'newly' formed one (established: $1.228 \pm 0.593$;

277 newly: $0.819 \pm 0.418$ ) and were higher in reproductively successful as compared to unsuccessful 278 pairs (Figure 2).

279

280 (3) Morphological measures

281 The body size index (BSI) was positively related to HCT, percentage of monocytes and H/L 282 ratio.

283

284 Discussion

285 Our results show that social and environmental factors interact with individual physiology in 286 a complex way. We found that in the free-living greylag geese investigated, haematocrit (HCT) 287 and differential leucocyte counts are seemingly contingent with a suite of endogenous (i.e. sex, 
288 age, raising condition), social (i.e. pair-bond status, pair-bond duration and parental experience)

289 and environmental factors (i.e. biologically relevant seasons).

290

291 Interestingly, pair-bond status showed a seasonal dependent relationship with several

292 haematological parameters: unpaired individuals had the highest HCT during the mating season

293 and H/L ratio was significantly higher in individuals who successfully raised young as compared

294 to individuals which failed to fledge offspring that year. Our results hint at a complex

295 relationship between an individual's social status within the flock, the seasonal patterns of

296 corticosterone and individual behavioural investment in order to optimize the own fitness, as

297 discussed by Kotrschal, Hirschenhauser \& Moestl (1998). In fact, during summer and winter, the

298 paired males with offspring had significantly higher corticosterone than both paired males

299 without offspring and singletons, whereas during the mating season, singletons had marginally

300 higher corticosterone than paired males. Furthermore, stress levels of all three male categories

301 were significantly higher during the mating season than during the rest of the year. Even

302 though we did not measure levels of corticosterone in the present study, a number of studies

303 confirm the close relationship between stress physiology and haematology (e.g. Gross \& Siegel

304 1983; Dickens, Earle \& Romero 2009).

305

306 Therefore we suggest that high HCT levels in unpaired individuals during the mating season

307 mirror social stress caused mainly by competition for a mate as well as by constrained access to

308 mates, whereas the haematological differences related to reproductive success might reflect

309 the costs of reproduction in successful geese. Such costs are one of the most significant 
310 components of life-history trade-offs and the immune system has been proposed as an

311 important link between reproductive investment and survival (Sheldon \& Verhulst 1996;

312 Deerenberg et al. 1997; French, Denardo \& Moore 2007; French, Moore \& Demas 2009;

313 Harshman \& Zera 2007; Cox et al. 2010).

315 Although earlier avian studies found higher HCT levels in males than in females (e.g.

316 cormorant, Phalacrocorax carbo, Balasch et al. 1974; kestrel, Falcus tinnunculus, Rehder, Bird \&

317 Laguë 1982; sparrowhawk, Falcus sparverius, Rehder \& Bird 1983), our results are in line with a

318 recent meta-analysis based on 36 published studies did not provide evidence for sex differences

319 in HCT (Fair, Whitaker \& Pearson 2007),).

320

321 Hence, the seasonal differences in relation to pair-bond status we found in our study may

322 reflect differences among greylag geese with different bonding status and energetics (De Graw,

323 Kern \& King 1979; Jenni et al. 2006). High H/L ratio may reflect physiological stress produced by

324 competition for partners during the mating season and frequent agonistic interactions among

325 the unpaired individuals, which may not enjoy the stress buffering effect of emotional social

326 support by social allies, notably by a pair partner (Scheiber et al. 2005). On the other hand, high

$327 \mathrm{H} / \mathrm{L}$ ratio may represent the costs of parental commitment for successfully breeding individuals.

329 Heterophils are the predominant immunological cell type within the Anseriformes (Lucas \&

330 Jamroz 1961). They form the first line of cellular defence against invading microbial pathogens

331 (Maxwell \& Robertson 1998). Findings in poultry suggest the $H / L$ ratio to be a reliable indicator 
332 of social stress (e.g. Gross \& Siegel 1983; Vleck et al. 2000). This is supported by other studies in

333 birds, which have shown that $\mathrm{H} / \mathrm{L}$ increases in response to a wide variety of stressors, including

334 long-distance migration (Owen \& Moore 2006) and parasitic infection (Davis, Cook \& Altizer

335 2004; Lobato et al. 2005; for a review see Davis, Maney \& Maerz 2008).

336

337 We suggest that the decrease of the percentage of lymphocytes and the increase of

338 heterophils (i.e. high $\mathrm{H} / \mathrm{L}$ ratio) may also reflect an increase in susceptibility to infections with

339 aging (Uciechowski \& Rink 2015), which affects several haematological parameters (Maxwell et

340 al. 1990; Maxwell \& Robertson 1998; Prinzinger, Misovic \& Nagel 2012). In fact, glucocorticoids

341 and oestrogens may reduce T-cell production (i.e. low lymphocytes levels) whereas androgens

342 may increase susceptibility to infections via elevated heterophils levels (Nelson et al. 2002).

343 However, as we did not directly measure glucocorticoid hormones, we can only speculate about

344 the relation between haematology and health. Notwithstanding, our results confirm

345 haematology's great potential in studies of ecology and in wild vertebrates, as recently

346 suggested by Maceda-Veiga et al. (2015).

347

348 Finally, our results showed that raising condition did affect haematological parameters,

349 suggesting that goose-raised individuals could cope better with the stressful mating season

350 than hand-raised individuals, as the latter showed significantly lower levels of leucocytes as

351 compared to goose-raised geese. Although raising history does not seem to affect other

352 reproductive parameters such as number and weight of eggs laid, hatching success or number 
353 of young fledged (Hemetsberger et al. 2010), this intrinsic aspect may deserve further attention

354 in the future when considering focal individuals.

355

356 In conclusion, our results indicate that the way social and intrinsic factors modulate

357 haematological parameters varied between seasons. Seasonal activities such as reproduction or

358 migration need to fine-tune physiology with weather conditions (e.g. Dorn et al. 2014; Frigerio

359 et al. 2004b; Romero, Reed \& Wingfield 2000). By and large, the investigated haematological

360 parameters varied with individual behavioural investment and stress load. Therefore they may

361 be considered as valid indicators of social burden.

362

\section{Acknowledgments}

364 We gratefully acknowledge Lara Cibulski, Oliver Elsaesser and Alexander Karl for helping with

365 catching geese in autumn 2012. Blood samples were analysed at the Clinical Pathology Platform

366 of the University of Veterinary Medicine in Vienna (Head Prof. Dr. I. Schwendenwein).

367

368

References

369

Alberts SC, Sapolsky RM, Altmann J. 1992. Behavioral, endocrine, and immunological correlates of

370 immigration by an aggressive male into a natural primate group. Hormones and Behavior, 26: 167-178.

371 Arfuso F, Fazio F, Rizzo M, Marafioti S, Zanghì E, Piccione G. 2016. Factors affecting the haematological

372 parameters in different goat breeds from Italy. Annals of Animal Science, DOI: 10.1515/aoas-2015-0094.

373 Aureli F, Preston SD, de Waal FBM. 1999. Heart rate response to social interactions in free moving

374 Rhesus macaques: a pilot study. Journal of Comparative Psychology 113: 59-65.

375 Averbeck C. 1992. Haematology and blood chemistry of healthy and clinically abnormal Great

376 Blackbacked Gulls (Larus marinus) and Herring Gulls (Larus argentatus). Avian Pathology, 21: 215-223.

377 Balasch J, Palomeque J, Palacios L, Musquera S, Jimenez M. 1974. Hematological values of some great 378 flying and aquatic-diving birds. Comparative Biochemistry and Physiology, 49A: 137-145. 
379 Bearhop S, Griffiths R, Orr K, Furness RW. 1999. Mean corpuscular volume (MCV) as a measure of

380

381

382

383

384

385

386

387

388

389

390

391

392

393

394

395

396

397

398

399

400

401

402

403

404

405

406

407

408

409

410

411

412

413

414

415

416 condition in birds. Ecology Letters, 2: 352-356.

Bortolotti GR, Mougeot F, Martinez-Padilla J, Webster LMI, Piertney SB. 2009. Physiological Stress Mediates the Honesty of Social Signals. PLOS ONE, 4(3): e4983. doi:10.1371/journal.pone.

Burnham KP. 2004. Multimodel inference: Understanding AIC and BIC in model selection. Sociological Methods \& Research, 33(2): 261-304.

Burnham KP, Anderson DR. 2002. Model selection and multimodel inference: a practical informationtheoretic approach. New York: Springer.

Cooper JE 1975. Haematological investigation in east African birds of prey. Journal of Wildlife Diseases, 11: 389-394.

Cox RM, Parker EU, Cheney DM, Liebl AL, Martin LB, Calsbeek R. 2010. Experimental evidence for physiological costs underlying the trade-off between reproduction and survival. Functional Ecology, 24: 1262-1269. doi: 10.1111/j.1365-2435.2010.01756.x

Davis AK, Cook KC, Altizer S. 2004. Leukocyte profiles of House Finches with and without mycoplasmal conjunctivitis, a recently emerged bacterial disease. Ecohealth, 1: 362-373.

Davis AK, Maney DL, Maerz JC. 2008. The use of leukocyte profiles to measure stress in vertebrates: a review for ecologists. Functional Ecology, 22: 760-772.

Dawson RD, Bortolotti GR. 1997a. Are avian hematocrits indicative of condition? American kestrel as a model. Journal of Wildlife Management, 61: 1297-1306.

Dawson RD, Bortolotti GR. 1997b. Variation in haematocrit and total plasma proteins of nestling American kestrels (Falco sparverius) in the wild. Comparative Biochemistry and Physiology A, 117: 383390.

De Graw WA, Kern MD, King JR. 1979. Seasonal changes in the blood composition of captive and freeliving white-crowned sparrows. Journal of Comparative Physiology, 129B: 151-162.

Deerenberg C, Apanius V, Daan S., Bos N. 1997. Reproductive effort decreases antibody responsiveness. Proceedings of the Royal Society B, 264: 1021-1029.

de Vries AC, Glasper ER, Detillion CE. 2003. Social modulation of stress responses. Physiology and Behavior, 79: 399-407.

Dickens MJ, Earle KA, Romero LM. 2009. Initial transference of wild birds to captivity alters stress physiology. General and Comparative Endocrinology, 160: 76-83.

Dorn S, Wascher CAF, Moestl E, Kotrschal K. 2014. Ambient temperature and air pressure modulate hormones and behaviour in Greylag geese (Anser anser) and Northern bald ibis (Geronticus eremita). Behavioural Processes, 108: 27-35.

Drent RH, Daan S. 1980. The Prudent Parent: Energetic Adjustments in Avian Breeding. Ardea, 68: 225258. DOI: http://dx.doi.org/10.5253/arde.v68.p225

Dufva R, Allander K. 1995. Intraspecific variation in plumage coloration reflects immune response in Great Tit (Parus major) males. Functional Ecology, 9: 785-789.

Fair J, Whitaker S, Pearson B. 2007. Sources of variation in haematocrit in birds. Ibis, 149: 535-552. 
417 French SS, Denardo DF, Moore MC. 2007. Trade-offs between the reproductive and immune systems:

418 facultative responses to resources or obligate responses to reproduction? American Naturalist, 170: 7941989.

420 French SS, Moore MC, Demas GE. 2009. Ecological immunology: the organism in context. Integrative and 421 Comparative Biology, 49: 246-253.

422 Frigerio D, Weiß B, Dittami J, Kotrschal K. 2003. Social allies modulate corticosterone excretion and 423 increase success in agonistic interactions in juvenile hand-raised greylag geese (Anser anser). Canadian 424 Journal of Zoology, 81: 1746-1754.

425 Frigerio D, Hirschenhauser K, Moestl E, Dittami J, Kotrschal K. 2004a. Experimentally elevated 426 testosterone increases status signalling in male Greylag geese (Anser anser). Acta Ethologica, 7: 9-18.

427 Frigerio D, Dittami J, Moestl E, Kotrschal K. 2004b. Excreted corticosterone metabolites co-vary with 428 ambient temperature and air pressure in male Greylag geese (Anser anser). General and Comparative 429 Endocrinology, 137: 29-36.

430 Gavett AP, Wakeley JS. 1986. Blood constituents and their relation to diet in urban and rural house 431 sparrow. Condor, 88: 279-284.

432 Goymann W, Villavicencio, CP, Apfelbeck B. 2015. Does a short-term increase in testosterone affect the 433 intensity or persistence of territorial aggression? - An approach using an individual's hormonal reactive 434 scope to study hormonal effects on behaviour. Physiology \& Behavior, 149, 310-316.

435 Green AJ. 2001. Mass/Length Residuals: Measures of Body Condition or Generators of Spurious Results? 436 Ecology, 82: 1473-1483.

437 Gross WB, Siegel HS. 1983. Evaluation of the heterophil/lymphocyte ratio as a measure of stress in 438 chickens. Avian Diseases, 27: 972-979.

439 Gross WB, Siegel, PB. 1986. Effects of initial and second periods of fasting on heterophil/lym-phocyte 440 ratios and body weight. Avian Diseases, 30: 345-346.

441 Harrison GJ, Harrison LR. 1986. Clinical avian medicine and surgery. WB Saunders, London.

442 Harshman LG, Zera AJ. 2007. The cost of reproduction: the devil in the details. Trends in Ecology and 443 Evolution, 22: 80-86.

444 Hellgren EC, Vaughan MR, Kirkpatrick RL. 1989. Seasonal patterns in physiology and nutrition of black 445 bears in Great Dismal Swamp, Virginia-North Carolina. Canadian Journal of Zoology, 67: 1837-1850.

446 Hemetsberger J. 2001. Die Entwicklung der Gruenauer Graugansschar seit 1973. In: Kotrschal K, Mueller 447 G, Winkler H, eds. Konrad Lorenz und seine verhaltensbiologischen Konzepte aus heutiger Sicht. Fuerth 448 (Germany): Filander Verlag, 249-260.

449 Hemetsberger J. 2002. Populationsbiologische Aspekte der Grünauer Graugansschar Anser anser. PhD 450 Thesis, University of Vienna, Vienna, Austria.

451 Hemetsberger J, Scheiber IBR, Weiß BM, Frigerio D, Kotrschal K. 2010. Influences of socially involved 452 hand-raising on life history and stress responses in greylag geese. Interdisciplinary Studies, 11(3): 380 453395.

454 Hemetsberger J, Scheiber IBR, Weiß BM. 2013. Greylag geese: from general principle to the Konrad 455 Lorenz flock. In: Scheiber IBR, Weiß BM, Hemetsberger J, Kotrschal K, eds. The social life of Greylag 456 Geese - Patterns, Mechanisms and Evolutionary Function in an Avian Model System. Cambridge 457 University Press, Cambridge, UK, 3-25. 
458 Hirschenhauser K, Moestl E, Kotrschal K. 1999a. Seasonal Patterns of Sex Steroids Determined from

459 Feces in Different Social Categories of Greylag Geese (Anser anser). General and Comparative

460 Endocrinology, 114: 67-79.

461 Hirschenhauser K, Moestl E, Kotrschal K. 1999b. Within-pair testosterone co-variation and reproductive 462 output in greylag geese (Anser anser). Ibis, 141: 577-586.

463 Jenni L, Mueller S, Spina F, Kvist A, Lindstroem L. 2006. Effects of endurance flight on hematocrits in 464 migration birds. Journal of Ornithology 147: 531-542.

465 Johnsen TS, Zuk M. 1998. Parasites, morphology, and blood characters in male red jungle fowl during 466 development. Condor, 100: 749-752.

467 Kotrschal K, Hirschenhauser K, Moestl E. 1998. The relationship between social stress and dominance is 468 seasonal in greylag geese. Animal Behaviour, 55: 171-176.

469 Kotrschal K, Hemetsberger J., Weiß BM. 2006. Homosociality in male greylag geese (Anser anser):

470 Making the best of a bad situation. In: Vasey P, Sommer V, eds. Homosexual Behaviour in Animals: An

471 Evolutionary Perspective. Cambridge: Cambridge University Press, 45-76.

472 Kotrschal K, Scheiber IBR, Hirschenhauser K. 2010. Individual performance in complex social systems. In:

473 Kappeler P, ed. Animal Behaviour: Evolution \& Mechanism. Heidelberg: Springer Verlag, 121-148.

474 Kralj-Fiser S, Scheiber IBR, Kotrschal K, Weiß BM, Wascher CAF. 2010. Glucocorticoids enhance and 475 suppress heart rate and behaviour in time dependent manner in greylag geese (Anser anser). Physiology 476 \& Behavior, 100: 394-400.

477 Lebigre C, Alatalo RV, Kilpimaa J, Staszewski V, Siitari H. 2012. Leucocyte counts variation and measures 478 of male fitness in the lekking Black Grouse. Journal of Ornithology, 153(1): 95-102.

479 Lees JJ, Nudds RL, Folkow LP, Stokkan K-A, Codd JR. 2015. Understanding sex differences in the cost of 480 terrestrial locomotion. Proceedings of the Royal Society of London B, doi:10.1098/rspb.2011.1334

481 Lindstrom MJ, Bates DM. 1990. Nonlinear mixed effects models for repeated measures data. Biometrics, 482 46: 673-687.

483 Lobato E, Moreno J, Merino S, Sanz JJ, Arriero E. 2005. Haematological variables are good predictors of 484 recruitment in nestling pied flycatchers (Ficedula hypoleuca). Ecoscience, 12: 27-34. Lorenz K. 1988. Hier bin ich - wo bist du? Ethologie der Graugans. Piper Verlag, München, Germany. Lucas AM, Jamroz J. 1961. Atlas of Avian Hematology. US Dep. of Agricolture, Washington D.C.

487 Lynn SE, Hunt KE, Wingfield JC. 2003. Ecological factors affecting the adrenocortical response to stress in 488 Chestnut-collared and McCown's longspurs (Calcarius ornatus, Calcarius mccownii). Physiological and 489 Biochemical Zoology, 76: 566-576.

490 Maceda-Veiga A., Figuerola J, Martínez-Silvestre A, Viscor G, Ferrari N, Pacheco M. 2015. Inside the 491 Redbox: Applications of haematology in wildlife monitoring and ecosystem health assessment. Science 492 of the Total Environment, 514: 322-332.

493 Maxwell MH. 1993. Avian blood leucocyte responses to stress. World's Poultry Science Journal, 49: 3449443.

495 Maxwell MH, Robertson GW. 1998. The avian heterophil leucocyte: a review. World's Poultry Science 496 Journal, 54(02): 155-178. 
497 Maxwell MH, Robertson, GW, Spence S, McCorquodale CC. 1990. Comparison of haematological values

498 in restricted and ad libitum-fed domestic fowls: white blood cells and thrombocytes. British Poultry

499 Science, 31: 399-405.

500 McFarlane JM, Curtis SE. 1989. Multiple Concurrent Stressors in Chicks: 3. Effects on Plasma

501 Corticosterone and the Heterophil:Lymphocyte Ratio. Poultry Science, 68(4): 522-527

502 doi:10.3382/ps.0680522.

503 Metcalfe NB, Taylor AC, Thorpe JE. 1995. Metabolic rate, social status and life-history strategies in

504 Atlantic salmon. Animal Behaviour, 49(2): 431-436.

505 Nelson RJ, Demas GE, Klein SL, Kriegsfeld L. 2002. Seasonal Patterns of Stress, Immunefunction and

506 Desease. Cambridge University Press.

507 Ots I, Murumägi A, Hõrak P. 1998. Haematological health state indices of reproducing great tits:

508 methodology and sources of natural variation. Functional Ecology, 12: 700-707.

509 Owen JC, Moore FR. 2006. Seasonal differences in immunological condition of three species of thrushes.

510 Condor, 108: 389-398.

511 Owens IPF, Hartley IR. 1998. Sexual dimorphism in birds: why are there so many different forms of

512 dimorphism? Proceedings of the Royal Society London B, 265: 397-407. doi:10.1098/rspb.1998.0308.

513 Pinheiro J, Bates D, DebRoy S, Sarkar D and R Core Team. 2015. nlme: Linear and Nonlinear Mixed

514 Effects Models. $\mathrm{R}$ package version 3.1-121, http://CRAN.R-project.org/package=nlme, last retrieved

$515 \quad 05.08 .2015$.

516 Potti J, Moreno J, Merino S, Frías O, Rodriguez R. 1999. Environmental and genetic variation in the

517 haematocrit of fledgling pied flycatchers. Oecologia 120: 1-8.

518 Prinzinger R, Misovic A, Nagel B. 2012. Aviaere Haematologie - Das Vogelblut: Struktur, Funktion,

519 Diagnose und Parasiten. Cuvillier Verlag, Goettingen, Germany.

520 R Core Team 2015. R: A language and environment for statistical computing. R Foundation for Statistical

521 Computing, Vienna, Austria. URL http://www.R-project.org/, last accessed 05.08.2015.

522 Raveling DG. 1979. The annual cycle of body composition of Canada geese with special reference to

523 control of reproduction. Auk, 96: 234-252.

524 Rehder NB, Bird DM. 1983. Annual profiles of blood packed cell volumes of captive American kestrels.

525 Canadian Journal of Zoology, 61: 2550-2555.

526 Rehder NB, Bird DM, Laguë PC. 1982. Variation in blood packed cell volume of captive American kestrels.

527 Comparative Biochemistry and Physiology 72A: 105-109.

528 Rehder NB, Bird DM, Laguë PC, Mackay C. 1982. Variation in selected hematological variables of captive 529 redtailed hawks. Journal of Wildlife Diseases, 18: 105-109.

530 Romero ML, Reed JM, Wingfield JC. 2000. Effects of weather on corticosterone response in wild free-

531 living passerine birds. General and Comparative Endocrinology, 118: 113-122.

532 Saino N, Cuervo JJ, Krivacek M, de Lope F, Møller AP. 1997. Experimental manipulation of tail ornament

533 size affects hematocrit of male barn swallows (Hirundo rustica). Oecologia 110: 186-190.

534 Sachser N, Duerschlag M, Hirzel D. 1998. Social relationships and the management of stress.

535 Psychoneuroendocrinology, 23: 891-904. 
536 Scheiber IBR, Weiß BM. 2013. Beyond the pairbond: extended family bonds and female-centred clan

537 formation. In: Scheiber IBR, Weiß BM, Hemetsberger J, Kotrschal K, eds. The social life of Greylag Geese

538 - Patterns, Mechanisms and Evolutionary Function in an Avian Model System. Cambridge University

539 Press, Cambridge, UK, 105-118.

540 Scheiber IBR, Weiß BM, Frigerio D, Kotrschal K. 2005. Active and passive social support in families of

541 Greylag geese (Anser anser). Behaviour, 142: 1535-1557.

542 Scheiber IBR, Kotrschal K, Weiß BM. 2009. Benefits of family reunions: Social support in secondary

543 greylag goose families. Hormones and Behavior, 55: 133-138.

544 Sheldon BC, Verhulst S. 1996. Ecological immunology: costly parasite defences and trade-offs in

545 evolutionary ecology. Trends in Ecology and Evolution, 11: 317-321.

546 Senar JC, Polo V, Uribe F, Camerino M. 2000 Status signalling, metabolic rate and body mass in the

547 siskin: the cost of being a subordinate. Animal Behaviour, 59(1): 103-110.

548 Thompson SC, Raveling DG. 1988. Incubation behavior of Emperor geese compared with other geese:

549 Interactions of predation, body size, and energetics. Auk, 104: 707-716.

550 Uciechowski P, Rink L. 2015. Basophil, Eosinophil, and Neutrophil Functions in the Elderly. In: Massoud

551 A, Rezaei N, eds. Immunology of aging, Springer Verag.

552 van Oort H, Otter K, Fort KT, McDonell Z. 2007. Habitat, dominance, and the phenotypic quality of the 553 black-capped chickadees. Condor, 109: 88-96.

554 Verhulst S, Oosterbeek K, Bruinzeel LW. 2002. Haematological parameters, mass and moult status in

555 dunlins Calidris alpina preparing for spring migration. Avian Science, 2: 199-206.

556 Vinkler M, Schnitzer J, Munclinger P, Votýpka J, Albrecht T. 2010 Haematological health assessment in a

557 passerine with extremely high proportion of basophils in peripheral blood. Journal of Ornithology,

558 151(4): 841-849.

559 Vleck CM, Vertalino N, Vleck D, Bucher TL. 2000. Stress, corticosterone, and heterophil to lymphocyte

560 ratios in free-living Adélie penguins. Condor, 102: 392-400.

561 von Holst D. 1998. The concept of stress and its relevance for animal behaviour. Advances in Behaviour,

562 27: 1-131.

563 Wascher CAF, Scheiber IBR, Kotrschal K. 2008. Heart rate modulation in bystanding geese watching

564 social and non-social events. Proceedings of the Royal Society of London, 275(1643): 1653-1659.

565 doi:10.1098/rspb.2008.0146.

566 Wascher CAF, Arnold W, Kotrschal K. 2008. Heart Rate Modulation by Social Contexts in Greylag Geese

567 (Anser anser). Journal of Comparative Psychology, 122(1):100-107.

568 Wascher CAF, Scheiber IBR, Weiß BM, Kotrschal K. 2009. Heart rate responses to agonistic interactions 569 in greylag geese, Anser anser. Animal Behaviour, 77: 955-961.

570 Wascher CAF, Weiß BM, Arnold W, Kotrschal K. 2012. Physiological implications of pair-bond status in 571 greylag geese. Biology Letters, 8: 347-350. doi: 10.1098/rsbl.2011.0917.

572 Wingfield JC, Hegner RE, Lewis DM. 1991. Circulating levels of luteinizing hormone and steroid

573 hormones in relation to social status in the cooperatively breeding white-browed sparrow weaver,

574 Plocepasser mahali. Journal of Zoology, 225: 43-58. doi:10.1111/j.1469-7998.1991.tb03800.x 
575 Zakari FO, Ayo JO, Rekwot PI, Kawu MU. 2014. Effect of age, sex, physical activity and meteorological

576 factors on haematological parameters of donkeys (Equus asinus). Comparative Clinical Pathology, DOI

577 10.1007/s00580-014-2026-3

578 Zuk M., Johnsen TS, MacLarty T. 1995. Endocrine-immune interactions, ornaments and mate choice in 579 red jungle fowl. Proceedings of the Royal Society of London B, 260: $205-210$.

580

581

582 Authors' contributions

583 DF coordinated the study, conducted data collection on the field, participated in data analysis

584 and wrote the manuscript; SCL participated in the design of the study and in the collection of

585 field data; JH participated in the design of the study and in the collection of field data; KK

586 participated in the design of the study and wrote the manuscript; CAFW participated in the

587 design of the study, carried out the statistical analyses, wrote the manuscript. All authors gave

588 final approval for publication.

589

590

591 


\section{Table and Figures Legends}

\section{Table 1:}

594 Details about the number of sampled individuals and the number of collected samples per

595 season and category (i.e. sex, social status, rearing condition).

596

597 Table 2:

598 Model selection of analyses that examined factors affecting (a) haematocrit (HCT), (b)

599 haeterophily to lymphocytes (H/L) ratio, (c) leucocyte count and (d) percentage of monocytes.

600 Individual identity was fitted as a random term. Three subsets of data have been tested: (1) The

601 full-dataset included all 169 samples collected from 105 individuals. Subset (2) included data

602 from male-female pair bonded individuals (68 samples from 50 individuals). (3) Only data from

603 individuals from which morphological measurements were collected was included (116 samples

604 from 70 individuals). LogLik: log-likelihood, AICc: second order Akaike's Information Criterion.

$605 \triangle$ AICc: the difference between the best model and each other possible model

606

607 Table 3:

608 Results of the full statistical models. Models for each response variable of all three data subsets

609 ( 1 = full dataset, 2 = paired individuals, 3 = body measures) are presented. Factors in bold are

610 significant $(p \leq 0.05)$.

611

612 Figure 1: 
613 Haematocrit in relation to season and pair-bond status. Gray circles represent individuals with

614 offspring (i.e. family); black circles represent paired individuals without offspring; plain circles

615 represent unpaired individuals. Circles indicate median, error bars represent interquartile

616 ranges (lower: 25th and upper: 75th percentile).

617

618 Figure 2:

619 Heterophil to lymphocyte $(\mathrm{H} / \mathrm{L})$ ratio in relation to individuals' reproductive success (both sexes

620 combined). Circles indicate median, error bars represent interquartile ranges (lower: 25th and

621 upper: 75th percentile).

622 


\section{Table 1:}

624 Details about the number of sampled individuals and the number of collected samples per

625 season and category (i.e. sex, social status, rearing condition).

626

\begin{tabular}{|c|c|c|c|c|c|c|c|c|c|c|c|}
\hline \multirow{4}{*}{ 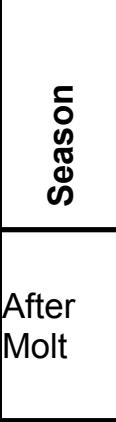 } & \multirow{4}{*}{ 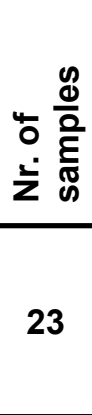 } & \multirow{4}{*}{ 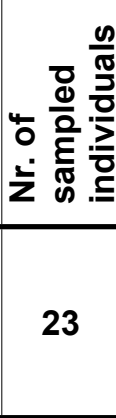 } & \multicolumn{2}{|c|}{ 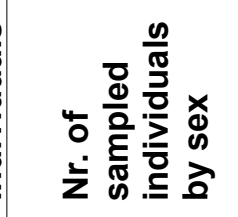 } & \multirow{2}{*}{ 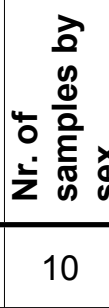 } & \multicolumn{2}{|c|}{ 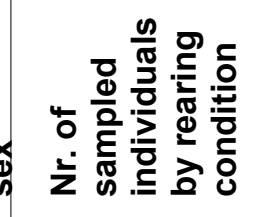 } & \multirow{2}{*}{ 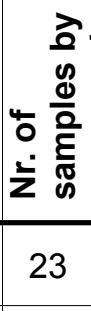 } & \multicolumn{2}{|c|}{ 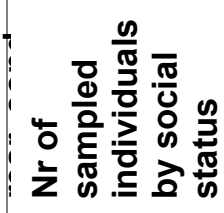 } & \multirow{2}{*}{ 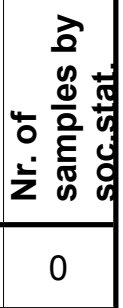 } \\
\hline & & & Males & 10 & & $\begin{array}{l}\text { goose- } \\
\text { raised }\end{array}$ & 23 & & single & 0 & \\
\hline & & & Females & 13 & 13 & hand-raised & 0 & 0 & paired & 0 & 0 \\
\hline & & & & & & & & & family & 23 & 23 \\
\hline \multirow{3}{*}{$\begin{array}{l}\text { Autum } \\
\mathrm{n}\end{array}$} & \multirow{3}{*}{82} & \multirow{3}{*}{73} & Males & 37 & 40 & $\begin{array}{l}\text { goose- } \\
\text { raised }\end{array}$ & 37 & 37 & single & 8 & 8 \\
\hline & & & Females & 36 & 42 & hand-raised & 36 & 45 & paired & 39 & 48 \\
\hline & & & & & & & & & family & 26 & 26 \\
\hline \multirow{3}{*}{ Mating } & \multirow{3}{*}{64} & \multirow{3}{*}{61} & Males & 40 & 42 & $\begin{array}{l}\text { goose- } \\
\text { raised }\end{array}$ & 39 & 39 & single & 16 & 18 \\
\hline & & & Females & 21 & 22 & hand-raised & 22 & 25 & paired & 30 & 31 \\
\hline & & & & & & & & & family & 15 & 15 \\
\hline
\end{tabular}

627 
629 Table 2:

630 Model selection of analyses examining factors affecting (a) haematocrit (HCT), (b) haeterophily

631 to lymphocytes ratio ( $\mathrm{H} / \mathrm{L}$ ratio), (c) leucocyte count and (d) percentage of monocytes.

632 Individual identity was fitted as a random term. Three subsets of data have been tested: (1) the

633 full-dataset included all 169 samples collected from 105 individuals; subset (2) included data

634 from male-female pair bonded individuals (68 samples from 50 individuals); subset (3) included

635 only data from individuals from which morphological measurements were collected (116

636 samples from 70 individuals). LogLik: log-likelihood; AICc: second order Akaike's Information

637 Criterion; $\triangle \mathrm{AIC}$ : difference between the best model and each other possible model.

638

\begin{tabular}{|l|l|l|l|l|}
\hline Models & df & LogLik & AIC & AICC \\
\hline (1a) Full-dataset: HCT & & & & \\
\hline $\begin{array}{l}\text { Sex, age, raising history, season, season*sex, season*age, } \\
\text { season*raising-status }\end{array}$ & 10 & 242.574 & -463.757 & 0 \\
\hline Pair-bond status, season, season*pair-bond status & 6 & 233.649 & -454.78 & 8.976 \\
\hline Season & 4 & 230.983 & -453.722 & 10.034 \\
\hline Sex, age, raising history & 6 & 219.471 & -426.423 & 37.333 \\
\hline Pair-bond status & 4 & 215.376 & -422.508 & 41.248 \\
\hline $\begin{array}{l}\text { Sex, age, raising history, pair-bond status, pair-bond } \\
\text { status*sex, pair-bond status*age, pair-bond status*raising } \\
\text { status }\end{array}$ & 8 & 218.177 & -419.454 & 44.302 \\
\hline Null model & 3 & 207.589 & -409.032 & 54.724 \\
\hline (1b) Full-dataset: H/L ratio & & & & \\
\hline Pair-bond status, season, season*pair-bond status & 6 & -196.356 & 405.23 & 0 \\
\hline $\begin{array}{l}\text { Sex, age, raising history, season, season*sex, season*age, } \\
\text { season*raising-status }\end{array}$ & 10 & -198.064 & 417.521 & 12.29 \\
\hline Season & 4 & -205.476 & 419.196 & 13.965 \\
\hline Sex, age, raising history & 6 & -207.444 & 427.406 & 22.176 \\
\hline $\begin{array}{l}\text { Sex, age, raising history, pair-bond status, pair-bond } \\
\text { status*sex, pair-bond status*age, pair-bond status*raising } \\
\text { status }\end{array}$ & 8 & -205.462 & 427.824 & 22.593 \\
\hline Pair-bond status & & & & \\
\hline Null model & 4 & -209.898 & 428.04 & 22.81 \\
\hline (1c) Full-dataset: leucocyte count & 3 & -213.424 & 432.994 & 27.763 \\
\hline
\end{tabular}




\begin{tabular}{|c|c|c|c|c|}
\hline Pair-bond status, season, season*pair-bond status & 6 & -1650.015 & 3312.549 & 0 \\
\hline $\begin{array}{l}\text { Sex, age, raising history, season, season*sex, season*age, } \\
\text { season*raising-status }\end{array}$ & 10 & -1646.151 & 3313.715 & 1.166 \\
\hline Season & 4 & -1656.422 & 3321.087 & 8.538 \\
\hline Null model & 3 & -1660.982 & 3328.11 & 15.56 \\
\hline Sex, age, raising history & 6 & -1658.534 & 3329.586 & 17.036 \\
\hline Pair-bond status & 4 & -1660.977 & 3330.199 & 17.649 \\
\hline $\begin{array}{l}\text { Sex, age, raising history, pair-bond status, pair-bond } \\
\text { status*sex, pair-bond status*age, pair-bond status*raising } \\
\text { status }\end{array}$ & 8 & -1657.008 & 3330.917 & 18.367 \\
\hline \multicolumn{5}{|l|}{ (1d) Full-dataset: percentage of monocytes } \\
\hline $\begin{array}{l}\text { Sex, age, raising history, season, season*sex, season*age, } \\
\text { season*raising-status }\end{array}$ & 10 & -480.402 & 982.197 & 0 \\
\hline Pair-bond status, season, season*pair-bond status & 6 & -485.006 & 982.531 & 0.334 \\
\hline Season & 4 & -491.375 & 990.995 & 8.797 \\
\hline Sex, age, raising history & 6 & -491.792 & 996.104 & 13.906 \\
\hline Pair-bond status & 4 & -494.597 & 997.439 & 15.241 \\
\hline Null model & 3 & -496.611 & 999.369 & 17.171 \\
\hline $\begin{array}{l}\text { Sex, age, raising history, pair-bond status, pair-bond } \\
\text { status*sex, pair-bond status*age, pair-bond status*raising } \\
\text { status }\end{array}$ & 8 & -493.017 & 1002.935 & 20.737 \\
\hline \multicolumn{5}{|l|}{ (2a) Pair-bonded individuals: HCT } \\
\hline Null model & 3 & 90.11 & -173.846 & 0 \\
\hline Pair-bond duration & 4 & 90.84 & -173.046 & 0.8 \\
\hline Parental experience & 4 & 90.276 & -171.918 & 1.928 \\
\hline \multicolumn{5}{|l|}{ (2b) Pair-bonded individuals: $\mathrm{H} /$ Lratio } \\
\hline Parental experience & 4 & -55.067 & 118.769 & 0 \\
\hline Pair-bond duration & 4 & -55.911 & 120.458 & 1.688 \\
\hline Null model & 3 & -58.245 & 122.865 & 4.095 \\
\hline \multicolumn{5}{|l|}{ (2c) Pair-bonded individuals: Leucocytes } \\
\hline Null model & 3 & -665.648 & 1337.672 & 0 \\
\hline Parental experience & 4 & -665.424 & 1339.484 & 1.812 \\
\hline Pair-bond duration & 4 & -665.49 & 1339.616 & 1.944 \\
\hline \multicolumn{5}{|l|}{ (2d) Pair-bonded individuals: Monocytes } \\
\hline Null model & 3 & -191.664 & 389.704 & 0 \\
\hline Pair-bond duration & 4 & -191.02 & 390.676 & 0.972 \\
\hline Parental experience & 4 & -191.293 & 391.222 & 1.518 \\
\hline \multicolumn{5}{|l|}{ (3a) Morphological measurements: HCT } \\
\hline $\mathrm{BSI}$ & 4 & 175.545 & -342.731 & 0 \\
\hline Null model & 3 & 146.71 & -278.206 & 55.525 \\
\hline \multicolumn{5}{|l|}{ (3b) Morphological measurements: H/Lratio } \\
\hline $\mathrm{BSI}$ & 4 & -146.399 & 301.158 & 0 \\
\hline
\end{tabular}




\begin{tabular}{|l|l|l|l|l|}
\hline Null model & 3 & -148.494 & 303.203 & 2.045 \\
\hline (3c) Morphological measurements: Leucocytes & & & & \\
\hline Null model & 3 & -1142.87 & 2291.954 & 0 \\
\hline BSI & 4 & -1142.073 & 2292.506 & 0.552 \\
\hline (3d) Morphological measurements: Monocytes & & & & \\
\hline BSI & 4 & -345.286 & 698.932 & 0 \\
\hline Null model & 3 & -349.29 & 704.794 & 5.862 \\
\hline
\end{tabular}

639

640 


\section{Table 3:}

642 Results of the full statistical models. Models for each response variable of all three data subsets

643 ( 1 = full dataset, 2 = paired individuals, 3 = body measures) are presented. Factors in bold are

644 significant $(p \leq 0.05)$.

\begin{tabular}{|c|c|c|c|c|}
\hline & Response variable & Estimate \pm SE & $\mathrm{t}$ value & $p$ \\
\hline \multicolumn{5}{|c|}{ (1) Haematocrit } \\
\hline & raising history & $-0.078 \pm 0.049$ & -1.574 & 0.118 \\
\hline & sex & $0.021 \pm 0.032$ & 0.669 & 0.504 \\
\hline & age & $0 \pm 0$ & 3.815 & $<0.001$ \\
\hline & season & $0.656 \pm 0.011$ & 5.715 & $<0.001$ \\
\hline & season*raising history & $0.03 \pm 0.019$ & 1.564 & 0.123 \\
\hline & season*sex & $-0.02 \pm 0.014$ & -1.425 & 0.159 \\
\hline & season*age & $0 \pm 0$ & -3.572 & $<0.001$ \\
\hline \multicolumn{5}{|l|}{ (1) $\mathrm{H} /$ Lratio } \\
\hline & pair-bond status & $1.245 \pm 0.346$ & 3.588 & $<0.001$ \\
\hline & season & $1.192 \pm 0.23$ & 5.177 & $<0.001$ \\
\hline & season*pair-bond status & $-0.563 \pm 0.135$ & -4.528 & $<0.001$ \\
\hline \multicolumn{5}{|c|}{ (1) Leucocytes } \\
\hline & pair-bond status & $-1.052 \pm 0.293$ & 3.545 & $<0.001$ \\
\hline & season & $-0.555 \pm 0.418$ & 1.32 & 0.186 \\
\hline & raising history & $0.801 \pm 0.384$ & 2.057 & 0.039 \\
\hline & sex & $0.087 \pm 0.253$ & 0.339 & 0.734 \\
\hline & age & $0.687 \pm 0.409$ & 1.644 & 0.1 \\
\hline & season*pair-bond status & $0.868 \pm 0.265$ & 3.212 & 0.001 \\
\hline & season*raising history & $-0.689 \pm 0.372$ & 1.812 & 0.069 \\
\hline & season*sex & $-0.161 \pm 0.252$ & 0.623 & 0.532 \\
\hline & season*age & $-0.691 \pm 0.416$ & 1.624 & 0.104 \\
\hline \multicolumn{5}{|c|}{ (1) Monocytes } \\
\hline & raising history & $-0.645 \pm 0.375$ & 1.698 & 0.089 \\
\hline & sex & $0.053 \pm 0.249$ & 0.212 & 0.831 \\
\hline & age & $0.516 \pm 0.405$ & 1.247 & 0.212 \\
\hline & season & $0.374 \pm 0.154$ & 2.369 & 0.017 \\
\hline & pair-bond status & $0.319 \pm 0.29$ & 1.085 & 0.277 \\
\hline & season*raising history & $0.471 \pm 0.362$ & 1.276 & 0.201 \\
\hline & season*sex & $-0.014 \pm 0.246$ & 0.056 & 0.955 \\
\hline & season*age & $-0.807 \pm 0.41$ & 1.924 & 0.054 \\
\hline & season*pair-bond status & $-0.004 \pm 0.261$ & 0.016 & 0.986 \\
\hline (2) $\mathrm{H} / \mathrm{L}$ ratio & & & & \\
\hline
\end{tabular}




\begin{tabular}{|l|l|l|l|l|}
\hline & pair-bond duration & $0.268 \pm 0.123$ & 2.111 & 0.034 \\
\hline & parental experience & $0.315 \pm 0.123$ & 2.493 & 0.012 \\
\hline (3) HCT & & & & \\
\hline & BSI & $0 \pm 0$ & 10.281 & $<0.001$ \\
\hline (3) H/L ratio & & & & \\
\hline & BSI & $0.003 \pm 0.001$ & 2.048 & 0.046 \\
\hline (3) Monocytes & & & & \\
\hline & BSI & $0.026 \pm 0.008$ & 3.248 & $\mathbf{0 . 0 0 2}$ \\
\hline
\end{tabular}

645

646 
647 Figure 1

648 Haematocrit in relation to season and pair-bond status. Gray circles represent individuals with

649 offspring (i.e. family); black circles represent paired individuals without offspring; plain circles

650 represent unpaired individuals. Circles indicate median, error bars represent interquartile

651 ranges (lower: 25th and upper: 75th percentile).

652

653

654

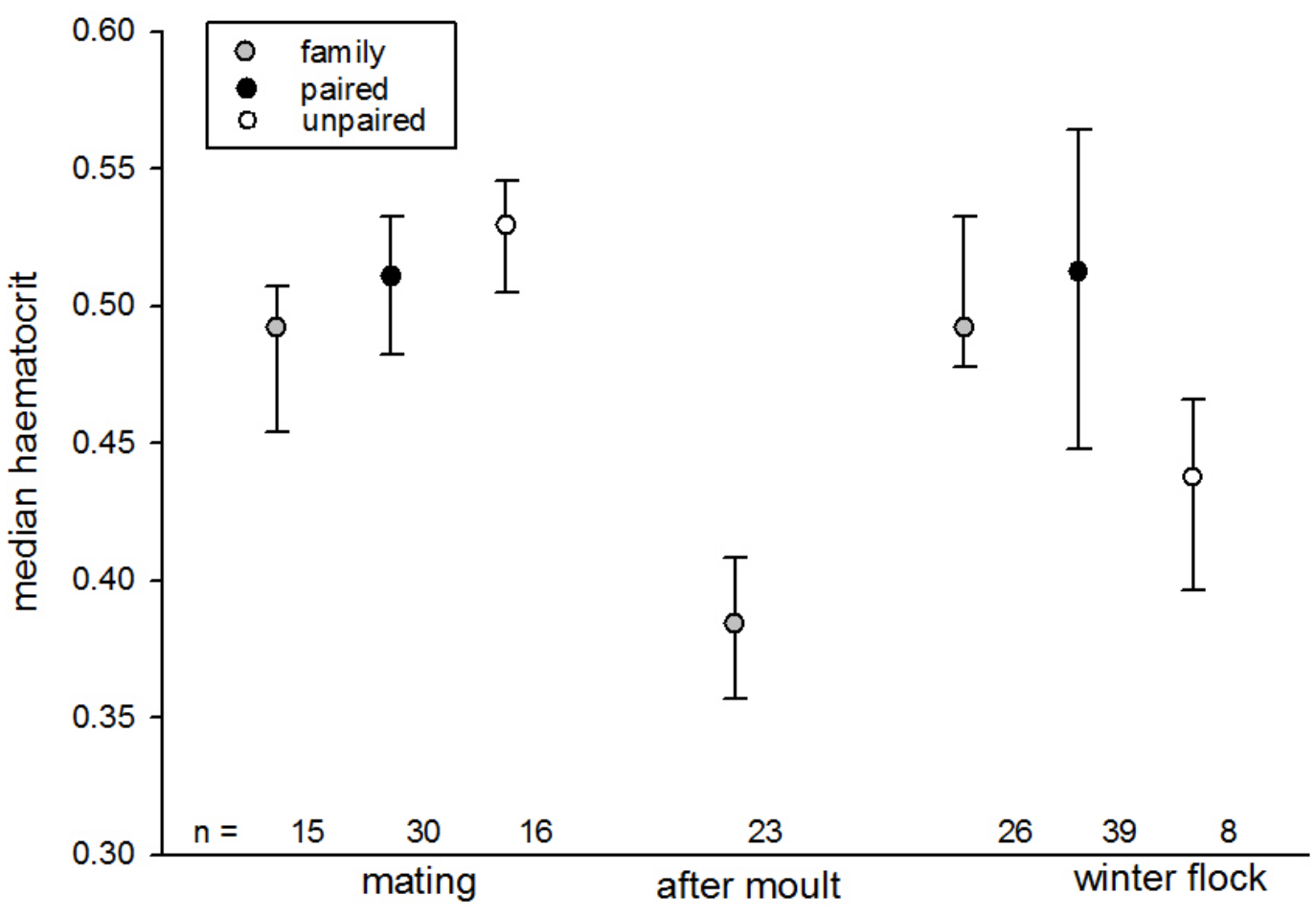

655

656

657

658

659 
660 Figure 2

661 Heterophil to lymphocyte $(\mathrm{H} / \mathrm{L})$ ratio in relation to individuals' reproductive success. Circles

662 indicate median, error bars represent interquartile ranges (lower: 25th and upper: 75th

663 percentile).

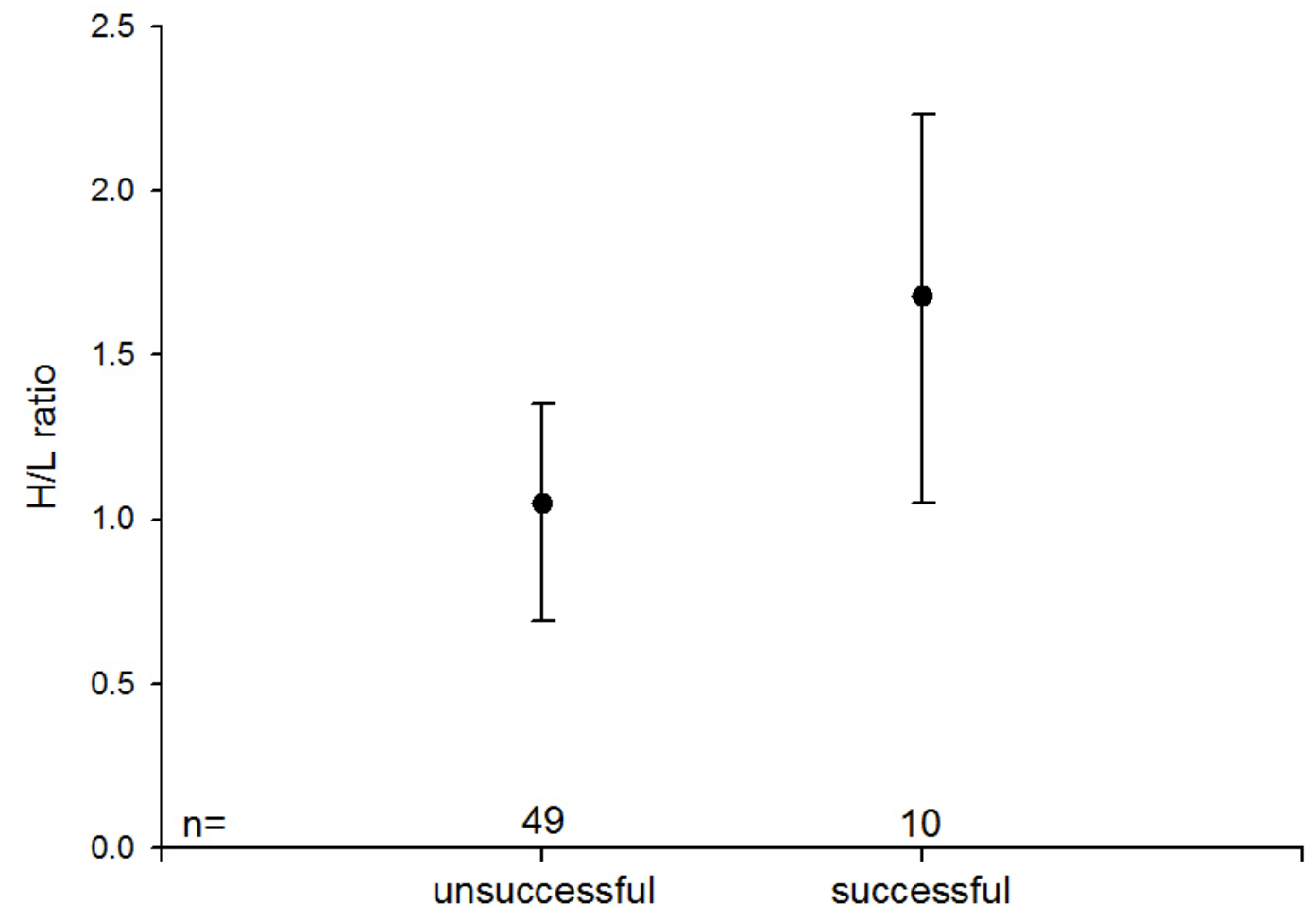

665

666 